East African Medical Journal Vol. 86 No.2 February 2009

PRIMARY OPEN ANGLE GLAUCOMA AND INTRAOCULAR PRESSURE IN PATIENTS WITH SYSTEMIC HYPERTENSION

A.O. Onakoya, MBBS, FWACS, FMCOphth, Guinness Eye Centre, J.N. Ajuluchukwu, MBBS, MMed, FMCP, Cardiology Unit, Department of Medicine and H.L. Alimi, MBBS, FWACS, FMCOphth, Lagos University Teaching Hospital College of Medicine, University of Lagos, Idi-Araba, PMB 12003, Lagos, Nigeria

Request for reprints to: Dr. A. O. Onakoya, Guinness Eye Centre, Lagos University Teaching Hospital/College of Medicine, University of Lagos, Idi-Araba, PMB 12003, Lagos, Nigeria

\title{
PRIMARY OPEN ANGLE GLAUCOMA AND INTRAOCULAR PRESSURE IN PATIENTS WITH SYSTEMIC HYPERTENSION
}

\author{
A.O. ONAKOYA, J.N. AJULUCHUKWU and H.L. ALIMI
}

\begin{abstract}
Objective: To investigate the association between Primary Open Angle Glaucoma (POAG), Intraocular Pressure (IOP) and systemic hypertension.

Design: Cross-sectional, convenient and controlled study.

Setting: Eye Clinic of the Lagos University Teaching hospital, Idi-Araba, Lagos, Nigeria.

Subjects: Consecutivenew patients with documented history of hypertension medication of over three months and current attendees at hypertension clinic of the same hospital were enrolled into the study.

Results: A total of $\mathbf{1 5 0}$ hypertensive patients and $\mathbf{5 0}$ age-sex matched controls were studied. Age range of hypertensives was 34-54 years and controls 31-71 years. The mean age for hypertensive group was 56 years $( \pm 12.95)$ and controls 54.76 years $( \pm 9.65)$ $\mathrm{p}>0.1$. The mean IOP was $28.45 \mathrm{mmHg}( \pm 10.3)$ in hypertensive group and $15.2 \mathrm{mmHg}$ $( \pm 5.09)$ in controls $(\mathrm{P}<0.001)$. POAG was present in $58(38.7 \%)$ of the hypertensive patients whilst only nine (18.0\%) had POAG in control group ( $p<0.01$ odds ratio: 22$)$. $1 \mathrm{OP}>21 \mathrm{mmHg}$ was found in $28(18.7))$ of hypertensive group and two $(4.0 \%)$ of the control ( $\mathrm{p}<0.01$ odds ratio 4.7 ).

Conclusion: Systemichypertension showed a modest positive association with elevated intraocular pressure. The strong relationship with IOP in part supports the association with POAG.
\end{abstract}

\section{INTRODUCTION}

Primary Open Angle Glaucoma (POAG) and systemic hypertension are diseases of public health importance contributing immensely to the burden of blindness, ill health and mortality in our country Nigeria and Worldwide (1-5).

Both disease conditions demonstrate similar epidemiological characteristics some of which are; higher prevalence with advancing age (4-6) increase prevalence with exponential increase in population ageing $(5,6)$, and almost a quarter to half of the affected individuals not aware that they suffer from the disease $(4,7)$. The clinical course of both conditions is more aggressive in blacks than, in Caucasians (8). Elevated Intraocular Pressure (IOP) has been proven by many studies as a major risk factor for the development of POAG $(7,9)$.

Systemic hypertension is a well recognised risk factor for elevated $10 P$ and several studies have shown a consistent association between elevated IOP and rise in systolic blood pressure and fewer with diastolic pressure (10-12).

POAG is the second common cause of blindness globally and in the South West Nigeria with a prevalence of $2-10 \%$ in individuals of over 40 years of age $(1,13-15)$. Systemic hypertension accounted for $20 \%$ of all cause mortality in blacks compared to $10 \%$ in whites with a gradient in its prevalence across African Diasporas ranging from 16\%) in West Africa to $26 \%$ in the Caribbean and $33 \%$ in the United States of America (16).

An evaluation of the impact of systemic hypertension on IOP and the incidence of POAG in these groups of patients is quite relevant in our environment as there has been no known report on the association in Nigerians.

Our study was designed to examine the relationship between systemic hypertension, intraocular pressure and primary open angle glaucoma in Nigeria. 


\section{MATERIALS AND METHODS}

Consecutive new patients at the Eye Clinic of Lagos University Teaching Hospital, Idi-Araba, with documented history of hypertension and / or use of antihypertensive medication of over three months and current attendees at hypertension clinic of the same hospital without previous ocular disorders between April-July 2004 were enrolled into the study. Age-sex matched non-hypertensive patients formed the control group.

POAG was defined by the presence of a demonstrable glaucomatous optic nerve head damage based on visual field and/ or optic disc findings. Elevated IOP was defined by IOP $>21 \mathrm{mmHg}$. Systemic hypertension was defined by self reported Physician diagnosis or from systolic blood pressure $\geq 140 / 90 \mathrm{mmHg}$ and or treatment history of three months or more.

Out of convenience the three investigators studied ten patients per clinic day culminating in a study period of four months.

All participants had detailed examination done according to standard protocols by the three authors between 9:00am-12noon at each visit in their respective clinics.

Assessment included:

(i) Detailed medical history interview

(ii) IOP measurements with Perkins hand held applanation Tonometer taking an average of two readings by the first author

(iii) Dilated bionocular Fundoscopy with $+78 \mathrm{D}$ assessment of optic nerve head with slit lamp by the first author.

(iv) Gonioscopy

(v) Blood pressure measurement with standardised mercury sphygmomanometer by the second author.

Excluded were patients with

(i) Known POAG patients currently on treatment (ii) Family history of POAG

(iii) Myopia

(iv) Diabetes mellitus

(v) Previous ocular trauma or diseases other than POAG.

Informed consent was obtained from all patients. Data analysis was done with Epi Info 2002.

\section{RESULTS}

A total of 150 patients with systemic hypertension and 50 normotensive age-sex matched controls were studied. The socio-demographic characteristics are shown in Table 1 . The mean $( \pm \mathrm{SD})$ age of hypertensive patients was $56.7 \pm 12.95$ years (range 34-84). The mean $( \pm S D)$ age for control group was $54.7 \pm 9.65$ years (range 31-71). There was no significant difference in the mean age of the two groups $p>0.1$. Male to female ratio was 1:1.3 and 1:1 for hypertensive and control group respectively. The mean $( \pm \mathrm{SD})$ IOP for the hypertensive group was $28.4 \pm 10.3 \mathrm{mmHg}$ (range 10-49mmHg) and control was $15.2 \pm 5.09 \mathrm{mmHg}$ (range $8-25 \mathrm{mmHg}$ ). There was a highly significant difference with $p<0.001$ in the mean IOP of the two groups. The mean IOP in the hypertensive group was remarkably high. Only one hypertensive patient was on $B$-adrenergic blocker for control of hypertension.

IOP $>21 \mathrm{mmHg}$ was found in $28(18.7 \%)$ of hypertensives and in only two $(4.0 \%)$ of the normotensive patients $(\mathrm{p}<0.01)$. The relative risk of elevated IOP in hypertensive individual is higher with an odds ratio of 4.7 at $951 \%<$, CI (Table 2).

Table 3 shows the association between the frequency of POAG in patients with systemic hypertension and normotensive individuals. POAG was found in $58(38.7 \%)$ of hypertensive patients and in nine $(18.0 \%)$ of normotensive individuals $(p<0.01)$. There is a significant different between the two groups. Individuals with systemic hypertension are at a risk of developing POAG with an odds ratio of $2: 2$.

Table 1

Socio-demographic characteristics of patients

\begin{tabular}{lcccc}
\hline & \multicolumn{2}{c}{ Hypertensives $(\mathrm{n}=150)$} & \multicolumn{2}{c}{ Controls $(\mathrm{n}=50)$} \\
Age group (years) & No. & $(\%)$ & No. & $(\%)$ \\
\hline $31-40$ & 12 & 8 & 6 & 12 \\
$41-50$ & 30 & 20 & 13 & 26 \\
$51-60$ & 58 & 38.7 & 14 & 28 \\
$61-70$ & 39 & 26 & 16 & 32 \\
$\geq 71$ & 11 & 7.3 & 1 & 2 \\
\hline Total & 150 & 100 & 50 & 100 \\
\hline
\end{tabular}

Age range 34-84 years 31-71 years

Mean age 56.7 years $( \pm 12.95) 54.7$ years $( \pm 9.65) \quad \mathrm{p}>0.1$

Sex Cases (\%) Controls (\%)

Male $\quad 66 \quad 44 \quad 25 \quad 50$

Female $84 \quad 56 \quad 25 \quad 50$

Ratio $1: 1.3 \quad 1: 1$ 
Table 2

Associations between elevated $\mathrm{lOP}$ and systemic hypertension

\begin{tabular}{lccc}
\hline Risk factor & IOP $\geq 21 \mathrm{mmhg}$ & $\mathrm{IOP}<21 \mathrm{mmhg}$ & Total \\
\hline Hypertension( + ) & 28 & 122 & 150 \\
Hypertension(-) & 2 & 48 & 50 \\
\hline Total & 30 & 170 & 200 \\
\hline
\end{tabular}

$\mathrm{P}<0.01$

Relative risk (odds ratio) 4.7

Table 3

Association between systemic hypertension and POAG

\begin{tabular}{lccc}
\hline Risk factor & POAG(+) & POAG(-) & Total \\
\hline Hypertension (+) & 58 & 92 & 150 \\
Hypertension (-) & 9 & 41 & 50 \\
\hline Total & 67 & 133 & 200 \\
\hline
\end{tabular}

$\mathrm{P}<0.01$

Relative risk (odds ratio) 2.2

\section{DISCUSSION}

The results of our study are indicative of a positive association between elevated IOP with the presence of POAG in patients with systemic hypertension.

Elevated IOP mean $>21 \mathrm{mmgH}$ was found in $18.7 \%$ of patients with systemic hypertension compared to $4.0 \%$ in controls ( $\mathrm{p}<0.01$ odds ratio 4.7 ) (Table 2). Individuals with systemic hypertension are therefore 4.7 times more at risk of developing elevated IOP than normotensive individuals.

Wuet al (10), Bengtsson (11), Bulpitt et al (12), and Shiose et al (17) in their studies on relationship between systemic hypertension and IOP found similar results. The possible mechanism is thought to be due the increased systemic blood pressure leading to increased production of aqueous humour by means of elevated ciliary artery pressure $(12,17)$. Another pathway is thought to emanate from the increased sympathetic tone in the vessels and the role of serum glucocorticoids (18-20).

In the Beaver Dam Eye study a significant correlation was found between changes in systemic blood pressure and changes in IOP, reduced systemic blood pressure was found associated with reduction of intraocular pressure (21).

The positive association could also be linked to the common pathogenefic mechanism at ciliary and renal tubular epithelial cells with regards to handling of sodium ( $\mathrm{Na}+$ ) excretion (20). Sodium is the primary promoter of body fluid and hence blood volume and cardiac output. Reduction in its excretion expands the extracellular fluid volume resulting in increase in cardiac output and therefore the blood pressure (22). Poor handling of $\mathrm{Na}+$ at the ciliary epithelial cells could lead to increase in intraocular pressure as a result of the volume expansion of the aqueous humour stemming from increased affinity for water.

POAG (high and normal tension) was detected in $38.7 \%$ of systemic hypertensives compared to $18.0 \%$ of age-sex adjusted controls with odds ratio of $2.2(\mathrm{p}<0.01)$ (Table 3$)$. Individuals with systemic hypertension are two times more likely to develop POAG than normotensive individuals.

Several population studies have confirmed these associations between systemic hypertension and POAG (19-24). Elevated IOP which is a known risk factor for developing POAG being positively associated with systemic hypertension is a major influence on the increased association.

Other reasons for the positive association of POAG and systemic hypertension could be adduced to the reduced optic nerve head and choroidal perfusion resulting from a decreased mean blood volume velocity in systemic hypertension, coupled with nocturnal dips (hypotension) experienced by those on antihypertensive treatments $(25,26)$. Vascular dysregulation with resultant hypotension at night is also an important predisposing factor contributing to the increased prevalence in patients with systemic hypertension $(26,27)$.

The positive relationship is also further supported by the common pathogenetic mechanism with altered sodium transportation at distal nephron and ciliary epithelial cells (20).

The similar epidemiological characterisics demonstrated by POAG and systemic hypertension 
further strengthens a possible link in their pathogenic pathways (4-7). Systemic hypertension is often a component of Syndrome X(metabolic syndrome) composed of dyslipidaemia, impaired glucose tolerance, diabetes mellitus and abdominal obesity (5). Girkin (25) et al in his study found that glaucoma patients had significantly higher rates of diabetes, lipid metabolism disorders, hypertension and migraines than controls. These associations could serve as a link to discovering the aetiology in primary open angle glaucoma. The question in mind is "Is glaucoma a component of metabolic syndrome?" A recent study done in South Korea to link elevated intraocular pressure and metabolic syndrome/insulin resistance revealed a higher level of mean intraocular pressures in participants with metabolic syndrome compared to those who did not have metabolic syndrome (29). The mean IOP tended to increase linearly with the presence of increasing numbers of components for metabolic syndrome (29). There is evidence of presence of insulin like growth factor 1 (IGF 1) receptor cells in bovine trabecular meshwork (30). It is thought that an abnormal down-regulation in IGF1 production may contribute to the pathogenesis of POAG. A possibility of promoting the autocrine action of IGF1 by trabecular meshwork cells to treat the disease is worth further investigation (30).

Further research at molecular level to link insulin resistance with POAG may give the desired answer to the aetiology and possibly a cure that has been most sought after in the treatment of POAG.

The study has also clearly demonstrated the need to critically screen every patient with systemic hypertension for POAG and subsequently reduce the ocular morbidity from the disease. The prominent role played by poor $\mathrm{Na}+$ excretion in pathogenesis of systemic hypertension may also set off a line of thought on the effect of salt consumption on the level of IOP and subsequently on open angle glaucoma.

However, our study having too few controls compared to cases (1:3) may not have given an accurate result representative of the reference population. Being a hospital based study, made it difficult to get many non-hypertensive patients in the studied age group visiting the hospital. Another limitation was the failure to take into consideration the current antihypertensive drugs the patients were on. It is known that patients using ( $B$ adrenergic blockers as their antihypertensive have better control of IOP and disease progression than others on Angiotensin Converting Enzyme inhibitors and Calcium channel blockers (20). This may be due to the natriuetic and channel blocking effect of the $\mathrm{B}$ blocker thereby leading to a reduction of the toxic effect of the extracellular $\mathrm{Na}+$ on the axons of retinal ganglion cells $(31,32)$. In our study only one patient was on $\&$ blocker for control of hypertension and was eliminated from analysis. This is however not surprising, as most of the hypertensive patients in our environment rarely used ( $B$-adrenergic blockers for control of hypertension (29), as evidenced by a study done by Alebiosu in a similar tertiary health institution in South West of Nigeria.

A larger population based study with a higher proportion of controls; taking into consideration the current antihypertensive the patient is using in our environment is therefore required for a clear and concise demonstration of the relationship.

\section{REFERENCES}

1. Olurin, O. Primary glaucoma in Nigeria. East Afr. Med. J. 1972; 49: 725-734.

2. Johnson, G.J. The adult glaucomas. J. Comm. Eye. Health. 2001; 14: 33-34.

3. Kaufman, J.S., Rotimi C.N., Brieger W,R., et al. The mortality risk associated with hypertension preliminary results of a prospective study in rural Nigeria. J. Hum. Hypertens. 1996; 10: 461-464.

4. Akinkugbe, O. O. Current epidemiology of hypertension in Nigeria. Arch. Ibadan. Med. 2000; 1: 3-5.

5. Kannel, W. B. Hypertensive risk assessment: Cardiovascular risk factors and hypertension. J. Clin. Hypertens. 2004; 6: 393-399.

6. Goldberg, I. Public health issues in glaucoma. Programme and abstracts of the World Glaucoma Congress; July 6-9, 2005; Vienna Austria. Opening session.

7. Leske, M. C., Connel A. M., Wu S. Y., et al. Incidence of open angle glaucoma. The Barbados eye studies. The Barbados Eye Studies Group. Arch. Ophthalmol. 2001; 119: 89-95.

8. Tielsch, J.M., Somnmer, A., Katz, J., et al. Racial variation in the prevalence of primary open angle glaucoma. The Baltimore Eye Survey. J. Amer. Med. Assoc. 1991; 226: 369-374.

9. Leske, M. C. The epidemiology of open angle glaucoma: A review. Amer. J. Epidemiol. 1983; 118: 166-191.

10. Wu S.Y and Leske M.C. Associations with intraocular pressure in the Barbados Eye Study Group. Arch. Ophthatmol. 1997; 115: 1572-1576.

11. Bengtsson, B. Some factors affecting the distribution of intraocular pressures in a population. Acta. Ophthalmol. (Copenh). 1972; 50: 33-46.

12. Bulpitt, C.J., Hodes C. and Everitt M.G. Intraocular pressure and systemic blood pressure. Brit. J. Ophthalmol. 1975; 59: 717-720.

13. Quigley, H.A. Glaucoma as a worldwide health problem. Program and abstracts of the World Glaucoma Congress; July 6-9 2005; Vienna Austria. Opening session. 
14. Burmann, R. R., Quigley, H.A., Baron, Y., et al. Prevalence of glaucoma in rural East African population. Invest. Ophthalmol. Vis. Sci. 2000; 41: 40-48.

15. Cook, C. Chronic glaucoma case finding and treatment in rural Africa. Some questions and answers. J. Comm. Eye Health. 2001; 14; 43-44.

16. Cooper, R. and Rotimi, C. Hypertension in blacks. Amer. J Hypertens. 1997; 10: 804-812.

17. Shiose, Y. and Kawase, Y. A new approach to stratified normal intraocular pressure in a general population. Amer. J. Ophthalmol. 1986; 101: 714-721.

18. Langman, M.J.S., Lancashire, R. J., Cheng, K.K. and Stewart, P.M. Systemic hypertension and glaucoma. Mechanisms in common and co-occurrence. Brit. J. Ophthalmol. 2005; 89: 960-963.

19. Klein, B.E.K., Klein, R. and Knudtson, M. D. Intraocular pressure and systemic blood pressure: Longitudinal perspective. The Beaver Dam Eye study. Brit. J. Ophthalmol. 2005; 89: 284-287.

20. Swales, J. D. In: Robertson J.I.S., ed. Handbook of hypertension, Volume 1; Clinical aspects of Hypertension. Amsterdam: Elsevier Science Publishers, 1983; 258.

21. Dielemans, I., Vingering, J. R., Algra, D., et al. Primary open angle glaucoma, Intraocular pressure and systemic blood pressure in the general elderly population. The Rotterdam study. Ophthalmol. 1995; 102: $54-60$
22. Mitchell, P., Lee, A. J., Rochtchina, E. and Wang, J.J. Open angle glaucoma and systemic hypertension: The blue mountains eye study. J. Glaucoma. 2004; 13: 19-26.

23. Grunwald, J.E., Piltz, J., Harriprasad, S.M., Dupont, J. and Maguire M.C. Optic nerve head blood flow in glaucoma: Effect of systemic hypertension. Amer. Ophthalmol. 1999; 127: 516-522.

24. Graham, S. L. and Drance, S. M. Nocturnal hypotension: role in glaucoma progression. Surv. Ophthalmol. 1999; 43 Supp: 510-516.

25. Girkin, C. A. Hypothyroidism is associated with glaucoma risk. Ophthalmol. 2004; 111: 1649-1652.

26. Oh, S.W., Lee S., Park, C. and Kim, D.J. Elevated intraocular pressure is associated with insulin resistance and metabolic syndrome. Diabetes Metab. Res. 2005; 21: 434-440.

27. Cao, Y., PfaffI, M.W., Da, B. and Wei H. Insulin like growth factor 1 (IGF-1) mRNA and IGF-1 protein: Expression in cells of the trabecular meshwork of the bovine eye. Ophthalmologe. 2002; 99: 555-558.

28. Taylor, C. P. and Meldrum B.S. Na+ channels as targets for neuroprotective drugs. Trends Pharmacol. Sci. 1995; 16: 309.

29. Alebiosu, C. O. Antidiabetics/ Antihypertensives prescription profile in OSUTH, Sagamu and environment. Nig. J. Clin. Pract. 2004; 7: 15-20. 